\title{
Crowd-sourcing Thermal (dis)Comfort
}

\author{
Stephen Snow \\ University of Southampton \\ s.snow@soton.ac.uk
}

\author{
Frederik Auffenberg \\ University of Southampton \\ fa1c12@ecs.soton.ac.uk
}

\author{
M.C. Schraefel \\ University of Southampton \\ mc@ecs.soton.ac.uk
}

\begin{abstract}
This paper details our work towards designing a system for crowd-sourcing responses on thermal comfort in naturally ventilated office buildings. We provide preliminary qualitative findings on the deployment of this system. Specifically, we explore the different human factors that led to our system being used as something akin to a digital complaints box and how we intend to adapt and leverage the system as a thermal comfort alerts system to better inform building managers.
\end{abstract}

Thermal comfort, natural ventilation, social factors, office.

\section{INTRODUCTION}

Thermal comfort relates to the rating of satisfaction with thermal conditions. It is a subjective rating of comfort gleaned from users, most commonly measured on a seven point scale between "cold" and "hot" and less commonly through sensors on the body. This data can then be used by intelligent thermostats to predict and adjust thermal comfort through manipulation of HVAC systems in buildings (Huang et al. 2015). However, such manipulation is not always possible in the absence of air conditioning, such as in naturally ventilated environments, which still make up a significant portion of the UK's building stock.

In this paper, we report on the deployment of a mechanism we developed to crowd-source thermal comfort in naturally ventilated offices. We are particularly interested in learning what factors affect people providing information about their thermal comfort. This builds upon our previous work which explored the different ways social factors may influence air quality in naturally ventilated environments (Snow et al. 2016). In this prior work we ascertained that otherwise rational actions towards making oneself more comfortable, such as opening a window, can be complicated by social factors such as politeness. For example some people wait until they are quite uncomfortable before asking if they might open a window; not wanting to make a fuss or disturb the "owner" of that window. In situations where a party external to the office controlled certain environmental aspects such as vents or heating, the delay between request and action represented a further barrier to occupants making desirable changes to their indoor air quality or thermal comfort (Snow et al. 2016).

Based on these previous findings, we wished to gather a better idea of the thermal comfort satisfaction of workers in naturally ventilated offices and compare this to quantitative measurements of temperature and air quality parameters

\section{CURRENT WORK}

Our initial design deployment involved the placement of 28 posters around several offices within a university building; all of which were naturally ventilated. Each poster featured a small portable "Joulo" temperature logger ${ }^{1}$ and an invitation for people to scan the QR code unique to that poster (or enter a unique URL) which linked to a portal where thermal comfort could be logged (Figure 1 below).

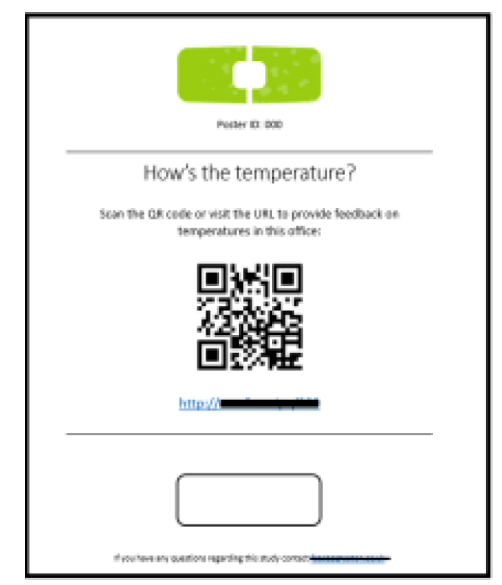

Figure 1: Poster

The portal consisted of two simple slide-able 7 point scales. One stating: "I'm feeling" (with a slider ranging from 'very cold' to 'very hot'), another: "I want it to be" (with a slider ranging from 'much colder' to 'much hotter') (refer Figure 2). Two humidity loggers were also deployed for reference.

\footnotetext{
${ }^{1}$ http://quby.com/en/solutions/joulo
} 
The deployment lasted 12 working days between the end of February and beginning of March 2016.

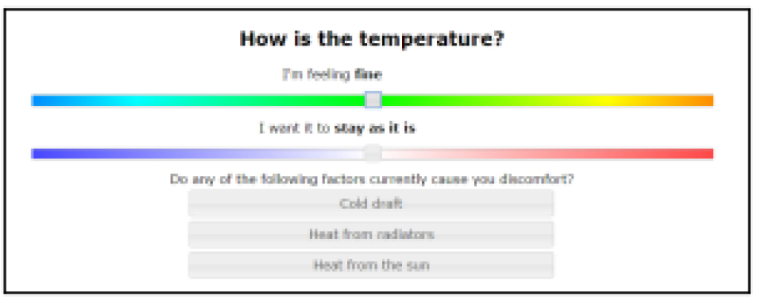

Figure 2: Interface

After the two week deployment we carried out 14 interviews with willing members of the offices in which we had deployed the posters. All participants were university employees, in the fields of HR and Finance. All interviews were transcribed, leading to over 400 minutes of qualitative transcript data. This is additional to the large quantitative dataset gathered from participants logging their thermal comfort votes and the temperature data logged by each Joulo over the course of the deployment.

\section{FINDINGS}

An uncomfortable office: Throughout the deployment, the system received a total 167 responses from 26 different users. It was quickly established from the logged temperature data that the offices were very warm (i.e. >23 degrees) most afternoons, even at the time of our winter deployment. The majority of responses input to the system related to employees feeling: "hot" or "very hot". Only $15 \%$ of all the votes registered correlated to employees wanting it to be cooler. In the interviews, many participants lamented the fact we had not carried out the study in summer, noting the heat in the offices was far worse during summer months: "...we shouldn't be working under these conditions" (P12). Participants listed different ways they coped with the heat in summer, including regular breaks, desk fans and working from home.

Motivations for participation: While participants all reported being happy to register their votes on the system, votes were cast primarily when people felt uncomfortable- mostly too hot. Less than $10 \%$ of all the 167 votes cast corresponded to people feeling neutral. Additionally, 7 of the 14 interview participants agreed they would likely have engaged with the system less if they did not believe the data would be shared with people who could make a difference, such as the university's Estates and Facilities. "I would probably just say, 'Oh, well what's the point then?'” (P14). This hints that people are less likely to engage in such as study if they are happy with their thermal comfort.

Interface design: All participants found the interface easy to use. A desire was expressed for more information about indoor air quality in the offices, such as real-time measurements of temperature, carbon dioxide and humidity. This was epitomised by an office worker moving one of the humidity loggers from its deployed location in a corridor into their office, simply because this logger had a digital display of humidity and temperature (which the Joulos did not) and the occupants wanted to know these parameters in their office.

\section{CONSIDERATIONS FOR FUTURE WORK}

We envisage our future work in this space entailing a larger-scale deployment of this system, such as in a library. In addition to suggestions for improvements to the user interface, the responses from the exit interviews point to a number of human factors requiring consideration that we did not anticipate. Namely, that most people did not feel it necessary (or simply forgot) to vote if they were happy with the temperature. It also seems likely that we only received as many responses as we did, because people saw the study as an opportunity of making their voice heard by those in power. Thus in some ways, our system took the form of a digital complaints box.

The realisation of this initially led us to question the validity of such a system for crowd-sourcing thermal comfort in this way. However after some consideration, we believe that following some adjustments, we in fact have a potentially very useful real-time thermal comfort alert system for public buildings. As such, an aim for our future deployment of this study is to provide a regular data feed of library users' thermal comfort to building managers. Even if this data is only comprised of votes of "too hot" or "too cold", this is still useful information that indicates areas of thermal discomfort that can be used to understand, map and better manage heating, cooling and ventilation activities in the library. Such a trial deployment allows for experimentation with building managers being able to change temperature or ventilation settings based on votes logged to the system. This also allows for two-way communication, e.g. building managers justifying their decisions to library users.

\section{REFERENCES}

Huang, C.C., Yang, R., Newman, W.W. (2015). The potential and challenges of inferring thermal comfort at home using commodity sensors. In Proceedings of UbiComp '15. ACM, 10891100.

Snow, S., Soska, A., Chatterjee, S.K., and M.C. Schraefel (2016). Keep Calm and Carry On: Exploring the Social Determinants of Indoor Environment Quality. In Proceedings of $\mathrm{CHI}$ 2016 Extended Abstracts. ACM, 1476-1482. 